\title{
"Overview of the Main Anti-SARS-CoV-2 Vaccines: Mechanism of Action, Efficacy and Safety" [Response To Letter]
}

\section{Maria Teresa Mascellino (D) Federica Di Timoteo Massimiliano De Angelis Alessandra Oliva (D)}

Department of Public Health and Infectious Diseases, Sapienza University, Rome, Lazio, Italy
Correspondence: Maria Teresa Mascellino Email mariateresa.mascellino@uniromal.it

\section{Dear editor}

We read with interest the comments by Syed Hasan Shuja et $\mathrm{al}^{1}$ regarding our article on the characteristics of the most common vaccines against COVID-19. ${ }^{2}$

In the present letter the authors underlined that in our review the vaccine by Sinopharm has not been mentioned which could possibly create panic and confusion in those people who were being given this vaccine in their vaccinal programs. ${ }^{1}$ We are very sorry for this involuntary misunderstanding. However, we must specify that this review was submitted to the journal at the end of April 2021, the corrected version after the comments of the reviewers was sent in June, the acceptance by the editor occurred in July followed by the publication on August 31, 2021. The authors of the letter are right when they say that the review is incomplete as the role of the vaccine by Sinopharm in the fight against the COVID-19 has not been taken into account. ${ }^{2}$ Nevertheless it must be considered that at the time of writing this vaccine was hardly mentioned or not mentioned at all because it was still in the early stages of its evaluation.

The WHO Strategic Advisory Group of Experts (SAGE) issued interim recommendations for the use of the Sinopharm vaccine (BIBP-CoV) developed by Beijing Institute of Biological Products Co. against COVID-19 on 29 April 2021. As new data becomes available, the WHO will update recommendations accordingly. ${ }^{3}$

Because of that, only now we have more precise information about this vaccine (the trade name is Covilo) which shows an efficacy of $79 \%$ in preventing symptomatic infection and hospitalization. No important side effects are detected other than pain at the site of injection, headache or fatigue. This vaccine is an inactivated vaccine (Vero cell) whose developers were Sinopharm + China National Biotec Group Co + Wuhan Institute of Biological Products. ${ }^{4}$ The vaccine, prepared with the inactivated whole virus, has several advantages, including low manufacturing cost, safety, and does not involve genetic manipulation. This approach uses technology that has been shown to work very well such as for the vaccines against influenza and polio. ${ }^{4}$

The study in Phase 3 (Trials ChiCTR2000034780) projected by Wuhan Institute of Biological Products Co., Ltd and by Beijing Institute of Biological Products Co., 
Ltd, evaluated the efficacy, the immunogenicity and the safety of the inactivated SARS-CoV-2 vaccine in a healthy population aged 18 years or older receiving in a random way two doses of the experimental Vero Cell vaccine, or placebo, at time 0 and 21 days after the first administration. ${ }^{5,6}$ The vaccine can be stored at $2-8^{\circ} \mathrm{C}$ but it should be protected from light. As it is well known, SARS-CoV-2 viruses undergo evolution, consequently some new virus variants may be associated with higher transmissibility and disease severity, The efficacy of the COVID-19 vaccine BIBP has not yet been evaluated in the context of widespread circulation of variants of concern (VOC) but this is assumed to be done shortly. ${ }^{3}$

The vaccine booster, after the two doses included in the normal vaccinal program, is currently contemplated for frail subjects with comorbidities, healthy workers, teachers, immunocompromised patients, and others. It is worth noting that at the time of our review, there was still no talk of the booster at all. In the near future the third dose of the vaccine might be extended to the entire population. Administration of a third dose of an inactivated virus vaccine (Vero cell) can boost the immune response and increase the duration of anamnestic responses against SARS-CoV-2. ${ }^{7}$ So far the approval by the FDA of the third dose refers only to the PfizerBioNTech (Comirnaty $\left.{ }^{\circledR}\right)$ vaccine anti-COVID-19 to allow for emergency use of a single booster dose to be administered at least six months after completion of the primary series for particular subjects. ${ }^{8}$

\section{Disclosure}

The authors declare no conflicts of interest for this communication.

\section{References}

1. Hasan Shuja S, Asad D, Samad Parekh A. Sinopharm: an unavoidable contender in the struggle against Covid. [Letter to the Editor, Infection and Drug Resistance 2021]. Infect Drug Resist. 2021;14:3899-3900. doi:10.2147/IDR.S338460

2. Mascellino MT, Timoteo F, De Angelis M, Oliva A. Overview of the main anti-SARS-CoV2 vaccines: mechanism of action, efficacy and safety. Infect Drug Resist. 2021;14:3459-3476. doi:10.2147/IDR.S315727

3. WHO Interim recommendations for use of the inactivated COVID-19 vaccine BIBP developed by China National Biotec Group (CNBG), Sinopharm; May 7, 2021. Available from: https://www.who.int/publica tions/i/item/WHO-2019-nCoV-vaccines-SAGE_recommendationBIBP-2021.1. Accessed October 13, 2021.

4. Ars toscana edited by C. Silvestri, Health Regional Agency in Toscana (Italy) and C. Stasi. Available from: https://www.ars.toscana.it/2-arti coli/4408-nuovo-coronavirus-vaccini-in-sperimentazione.html. Accessed October 23, 2021.

5. Al Kaabi N, Zhang Y, Xia S, et al. Effect of inactivated SARS-CoV-2 vaccines on symptomatic COVID-19 infection in adults: a Randomized Clinical Trial. JAMA. 2021;326(1):35-45. doi:10.1001/jama.2021.8565

6. A study to evaluate the efficacy, safety and immunogenicity of inactivated SARS-CoV-2 vaccines (Vero Cell) in healthy population aged 18 years old and above (COVID-19). ClinicalTrials.gov US National Library of Medicine (NIH). Available from: https://clinicaltrials.gov/ ct2/show/record/NCT04510207. Accessed October 13, 2021.

7. Wang K, Cao Y, Zhou Y, et al. A third dose of inactivated vaccine augments the potency, breadth, and duration of anamnestic responses against SARS-CoV-2. medRxiv. 2021. doi:10.1101/2021.09.02.21261735

8. FDA News release FDA authorizes booster dose of Pfizer-BioNTech COVID-19 vaccine for certain populations; September 22, 2021. Available from: https://www.fda.gov/news-events/pressannouncements/fda-authorizes-booster-dose-pfizer-biontech-covid-19vaccine-certain-populations. Accessed October 13, 2021.

\footnotetext{
Dove Medical Press encourages responsible, free and frank academic debate. The content of the Infection and Drug Resistance 'letters to the editor' section does not necessarily represent the views of Dove Medical Press, its officers, agents, employees, related entities or the Infection and Drug Resistance editors. While all reasonable steps have been taken to confirm the content of each letter, Dove Medical Press accepts no liability in respect of the content of any letter, nor is it responsible for the content and accuracy of any letter to the editor.
}

Infection and Drug Resistance

Dovepress

\section{Publish your work in this journal}

Infection and Drug Resistance is an international, peer-reviewed openaccess journal that focuses on the optimal treatment of infection (bacterial, fungal and viral) and the development and institution of preventive strategies to minimize the development and spread of resistance. The journal is specifically concerned with the epidemiology of antibiotic resistance and the mechanisms of resistance development and diffusion in both hospitals and the community. The manuscript management system is completely online and includes a very quick and fair peerreview system, which is all easy to use. Visit http://www.dovepress.com/ testimonials.php to read real quotes from published authors. 